\title{
O problema da substância na Doutrina da Essência (1813) de Hegel
}

The problem of substance in Hegel's Doctrine of Essence (1813)

\author{
Federico Orsini \\ platoniet@yahoo.it \\ (Pontifícia Universidade Católica do Rio Grande do Sul, Rio Grande do Sul,
}

\begin{abstract}
Resumo: 0 objetivo deste artigo é esclarecer os termos da apresentação crítica da substância na Doutrina da Essência (1813) de Hegel. Para tanto, procederei em três passos: em primeiro lugar, apresentarei o conteúdo intrinsecamente relacional da categoria da substância na Doutrina da Essência (1813); em segundo lugar, analisarei em que consiste a falha que impulsiona a ciência lógica a ultrapassar a relação da substancialidade; em terceiro lugar, comentarei sobre o sentido geral da refutação hegeliana do sistema espinosista.
\end{abstract}

Palavras-chave: $\quad$ substância; acidente; relação; refutação; Spinoza.
Abstract: The aim of this article is to clarify the way in which Hegel's Doctrine of Essence (1813) develops a critical presentation of the category of substance. To this end, I will proceed in three steps. In the first place, I will present the relational character of substance in the relevant place of the Doctrine of Essence (1813); in the second place, I will analyze the shortcoming which drives the logical science beyond the relation of substantiality; in the third place, I will make a few comments on the general sense of Hegel's refutation of Spinoza's system.

Keywords: substance; accident; relation; refutation; Spinoza.

DOI: http://dx.doi.org/10.11606/issn.2318-9800.v23i2p81-104

Introdução: posição do problema da substância na filosofia de Hegel

Como se sabe, o programa filosófico formulado por Hegel desde o Prefácio da Fenomenologia do Espírito (1807) é o seguinte: "segundo minha visão, que tem de se justificar somente por meio da apresentação do próprio sistema, tudo depende de apreender a verdade não [apenas] como substância, mas de igual modo como sujeito" (Hegel, 1969 - TW 3/22-23). Depois que a obra de Jena dissolveu progressivamente as pretensões de verdade do sujeito finito, aprisionado à oposição da consciência entre sujeito e objeto do saber, a execução do programa sistemático se encontra primeiramente na Ciência da Lógica (1812-1816), cujo propósito - cabe frisar - não é suprimir a substância para substituí-la com o sujeito, mas sim apresentar uma concepção não-subjetivista de sujeito enquanto resultado de uma autocrítica lógica da categoria de substância, a qual é vista como alicerce do ponto de vista do 
espinosismo. Em outras palavras, a relação sistemática entre substância e sujeito, pensado por sua vez como automovimento do conceito, não deve ser pensada nem como uma coordenação, nem como uma mera substituição, mas antes como uma superação ou suprassunção (Aufhebung), ou seja, como a negação-conservaçãoelevação de um conceito no seu sucessor lógico. ${ }^{1}$

O problema da substância é, antes de tudo, um problema lógico dentro de uma lógica dialético-especulativa que assume a tarefa de criticar de modo imanente a metafísica de Spinoza. A elaboração desse problema deve poder articular a resposta a três perguntas fundamentais: (i) Em que consiste o conteúdo puramente lógico da substância enquanto categoria considerada de modo puro (em si e para si)? (ii) Por que o estudo da ciência lógica não pode parar na substância? Ou seja, por que o lugar sistemático do exame da substância é simultaneamente o lugar da transição necessária da substância para o conceito? (iii) Em que modo essa transição configura uma refutação da metafísica de Spinoza?

No que segue, desenvolverei mais detalhadamente a primeira e a segunda pergunta, enquanto deixarei a resposta à terceira pergunta na forma de um esboço, cuja elaboração requer uma análise pormenorizada da conclusão da Lógica Objetiva e de sua articulação com a Lógica Subjetiva, análise essa que ultrapassa o foco da presente contribuição. Portanto, em conformidade com as perguntas colocadas, minha argumentação terá a seguinte estrutura: em primeiro lugar (seção 1), apresentarei o conteúdo intrinsecamente relacional da categoria da substância na Doutrina da Essência (1813); em segundo lugar (seção 2), analisarei em que consiste a falha ou o déficit que impede a ciência lógica de parar na relação da substancialidade; em terceiro lugar (seção 3), comentarei sobre o sentido geral da refutação hegeliana do sistema espinosista.

\section{O conteúdo da substância enquanto categoria da relação absoluta}

Desde Aristóteles, a metafísica norteou sua elaboração da questão pelo que existe a partir da questão: “O que é a substância?”. A análise aristotélica dessa categoria explicitou dois caracteres formais que a substância deve reunir: a autossubsistência (algo é substância se existe em si e não em outro, isto é, se não precisa existir em outro, mas existe em si e para si, separadamente dos demais entes) e a determinidade (nisso, possibilitando a resposta à pergunta: "por que somente

1 De acordo com Dieter Henrich, a relação entre a teoria do ser e aquela da essência pode ser elucidada por meio dos conceitos de "antecessor" e de "sucessor". Cf. Henrich, 1978, pp.230-235. Se uma teoria é sucessora da outra em vez de apenas substituir a outra, então a nova teoria tem de realizar o que a primeira realizou de tal modo que ela o realiza melhor do que a anterior. A mesma relação poderia ser utilizada para descrever a relação entre a teoria da substância e a teoria da subjetividade. 
certas coisas existem e não tudo?”). A apresentação hegeliana da substância consiste numa apresentação crítica da categoria metafísica da substância. Qual é aquele traço distintivo da metafísica da substância que torna necessária sua crítica lógica? A resposta de Hegel é clara: a incapacidade de reunir o requisito da autossubsistência com o requisito da determinidade, requisito este que remete à compreensão da relacionalidade constitutiva da substância. A Lógica da Essência é a "parte mais difícil" (Enciclopédia \$114, Observação) da Ciência da Lógica, porque a ela Hegel confia a solução do problema mais difícil da Lógica, a saber, apresentar a conexão interna da autossubsistência (Selbstständigkeit) e da relacionalidade das determinações do pensamento. Hegel se esforça de pensar de modo puramente conceitual essa conexão através do conceito de contradição, ao passo que o entendimento metafísico ou científico quer esquivar a contradição, mas acaba por reproduzi-la, pelo fato de justapor esses dois requisitos de modo inconsequente. A tarefa da Doutrina da Essência consiste em tornar explícita a contradição produzida irrefletidamente pelo entendimento. A contradição das determinações do entendimento é a contradição necessária entre a sua autossubsistência e a sua relacionalidade.

A este respeito, já fica claro que pensar o aspecto problemático da substância consiste precisamente em pensar sua contradição constitutiva. A exposição hegeliana desse problema ocupa um lugar específico da Doutrina da Essência (1813), a saber, o primeiro subcapítulo do terceiro capítulo ("A relação absoluta”) da terceira seção ("A efetividade”). Trata-se do subcapítulo que é intitulado "A relação da substancialidade" (Das Verhältnis der Substantialität). A apresentação do conteúdo relacional da substância procederá em três passos principais: em primeiro lugar (seção 1.1), tentarei circunscrever a peculiaridade da crítica à relação de substancialidade, diferenciando-a de outros quatro lugares lógicos da crítica da substância na Doutrina da Essência; em segundo lugar (seção 1.2), deter-me-ei na análise da relação da substancialidade e argumentarei a tese de que a categoria de substância não é, para Hegel, um fundamento de relações que nelas transcorrem, mas é ela mesma relação, precisamente uma configuração daquela relação que Hegel caracteriza como “relação absoluta” (absolutes Verhältnis); em terceiro lugar (seções 1.3-1.5), examinarei a estrutura da relação da substancialidade como cerne de uma ontologia da potência construída a partir da crítica da ontologia de Espinosa.

\subsection{Topologia da crítica à substância na Doutrina da Essência}

A crítica da substância na Doutrina da Essência (1813) não fica restrita à crítica da relação da substancialidade. Portanto, cabe indicar de modo preliminar os outros lugares dessa crítica, de modo a preparar o terreno para a análise subsequente da relação da substancialidade. No meu ver, a topologia crítica da substância se compõe 
de quatro lugares.

Em primeiro lugar, a lógica das determinações de reflexão no segundo capítulo da primeira seção ("A essência como reflexão dentro dela mesma”) fornece uma crítica da compreensão tradicional (principalmente, aristotélica) da proposição como expressão de uma relação entre substância e acidente (Iber, 1990, pp.263-264). De acordo com a interpretação hegeliana do tratado aristotélico sobre as Categorias, o sujeito está determinado como substrato firme de determinações, isto é, como o suporte ou o portador último de seus acidentes. A lógica das "determinações de reflexão" (Reflexionsbestimmungen) questiona a forma da proposição na medida em que mostra como os elementos da proposição se constituem. Portanto, ela expõe a exterioridade e nega a independência dos termos ou elementos da proposição, tal qual ela é pressuposta pela lógica formal aristotélica. De acordo com a compreensão aristotélica das categorias como gêneros supremos da predicação, as relações são determinações que sobrevêm ou inerem a um ente subjacente, isto é, a um substrato. Nesse sentido, a categoria de relação, assim como as outras categorias diferentes da substância, configura apenas uma predicação acidental, a saber, a atribuição a um sujeito de um predicado que pode não the pertencer necessariamente. A predicação acidental não expressa um vínculo essencial, ou seja, uma relação de identidade essencial entre sujeito e predicado, mas sim uma mera atribuição (Berti, 1993, pp.66-68.). Na lógica da reflexão, essa compreensão lógicometafísica se torna alvo de crítica na medida em que se mostra que a independência da relação ou a imediatidade do ser pressuposto pela reflexão é, na verdade, uma aparência (Schein) produzida pela própria reflexão. De modo específico, a passagem da "reflexão exterior" (äußere Reflexion) para a “reflexão determinante" (bestimmende Reflexion) é o contexto que permite articular a tensão entre ser posto (ou relacionalidade) e imediatidade (ou reflexão dentro de si) que habita cada produto da reflexão. O nome que Hegel dá aos produtos da reflexão determinante é “determinação de reflexão" (Reflexionsbestimmung) e o estudo das determinações de reflexão equivale a uma crítica da absolutização desses produtos (a saber: identidade, diferença, diversidade, oposição, contradição) por meio de supostas leis ou princípios do pensamento. Essa crítica constitui a consumação de uma teoria da relação enquanto tal, na qual são investigadas tanto a forma do relacionar quanto a relação entre relação e relacionados. No primeiro capítulo da Doutrina da Essência, Hegel desenvolve os modos formais da relação enquanto modos da reflexão pura: reflexão ponente, exterior e determinante. A reflexão determinante dá origem ao conceito de determinação de reflexão. As determinações de reflexão são "relações determinadas" (Hegel, 2017, p.94) que são idênticas consigo ou autossuficientes, apesar de elas terem sido geradas ou postas por aquela relação pura e absoluta que é a essência. A teoria das determinações de reflexão desenvolvida no segundo capítulo 
da Doutrina da Essência deriva cada determinação como “lado determinado" ou termo de relação e simultaneamente como "relação desse lado determinado enquanto determinado" (idem, p.52). A primeira crítica à substância é, portanto, uma crítica de toda ontologia vinculada à estrutura da predicação, caracterizada pela aparência de um primado dos termos sobre suas relações.

Em segundo lugar, a crítica da substância se configura como crítica da substância de Spinoza. Aqui é preciso observar o deslocamento que o conceito de substância recebe na passagem da metafísica antiga para a metafísica moderna. Enquanto para Aristóteles a substância indica simplesmente um tipo de entes, a saber, aqueles que encontramos em nossa experiência cotidiana e que subsistem em si, não em outro, a filosofia moderna radicaliza o critério da autossubsistência ou não-inerência em outro e se pergunta se e como ele pode ser satisfeito dentro de uma nova visão (matemática e relacional) da natureza, que rompeu com a visão aristotélica da natureza como cosmos, totalidade fechada e ordenada capaz de reunir uma pluralidade de essências qualitativamente e hierarquicamente distintas. A visão de Spinoza é que somente a natureza como um todo pode preencher o requisito da autossubsistência. A compreensão espinosana da natureza é metafísica na medida em que ele compreende os fenômenos naturais como modificações e efeitos de uma causa primeira única, ou seja, daquela que por sua vez não é efeito de nenhuma outra causa, nem da mesma espécie nem de qualquer outra espécie. A crítica hegeliana da relação entre natura naturans (substância e atributos) e natura naturata (conexão infinita dos modos finitos) de Spinoza ocorre no primeiro capítulo ("O absoluto") da terceira seção (“A efetividade”), onde Hegel oferece uma tradução lógico-dialética dos conceitos metafísicos expostos no primeiro livro da Ética de Spinoza.

Em terceiro lugar, a explicitação da crítica à substância de Spinoza continua na Observação que conclui a discussão crítica do "absoluto". Nessa Observação, Hegel compara a substância única de Spinoza com o sistema pluralista das substâncias individuais de Leibniz, mostrando a necessidade da complementaridade entre os dois sistemas ontológicos (Nunziante, 2001, pp.126-138). O resultado é que essa complementaridade não pode se realizar no terreno da categoria metafísica da substância. A objeção fundamental de Hegel é que a filosofia de Spinoza é um "pensar externo" (Hegel 2017, p. 200) porque não desenvolveu o princípio omnis determinatio negatio est até o conceito de negação absoluta ou negatividade autorrelacional. Neste respeito, Spinoza não ultrapassou uma exposição meramente negativa do absoluto, pois substituiu o ponto de vista da autodeterminação imanente da substância com a perspectiva de um sujeito finito. A crítica geral ao pensar externo se especifica em críticas direcionadas à falta de concatenação lógico-dialética entre os três momentos do absoluto espinosano. Quanto à substância, sua definição como causa sui tem o inconveniente de ser apenas uma definição, em vez de ser o resultado de um processo 
necessário das determinações reflexivas. Neste sentido, Spinoza não consegue mostrar a conexão necessária (genética) entre a categoria de substância e aquela de causa, por ele ter adotado o método de demonstração matemática que não lhe permite uma reflexão sobre as próprias categorias usadas como princípios. Quanto ao atributo, as críticas de Hegel são duas: (i) sua definição implica a intervenção de um terceiro - o entendimento - ao invés de se configurar como autodeterminação imanente à própria substância; (ii) os atributos são determinados como infinitos, mas, no final, são reduzidos a dois por causa da limitação de nosso entendimento, sem nenhuma outra explicação. A pluralidade dos atributos, portanto, não é demonstrada, mas fica um dado empírico. Quanto ao conceito de modo, o déficit é que Spinoza não explica o caráter determinado da relação do modo com a substância, pelo fato de o modo ser reduzido a algo imediatamente dado e existente em outro. Por causa disso, Hegel afirma que o sistema de Spinoza não conhece o modo como reflexão dentro de si (Reflexion in sich) da própria substância.

A exposição do sistema de Spinoza no primeiro capítulo da seção sobre a efetividade provocou e continua a provocar uma discussão intensa sobre se Hegel teria simplesmente equivocado Spinoza (Melamed, 2012), incorporando inadvertidamente uma lógica da pura afirmação a uma lógica da negatividade estranha ao filósofo holandês (Macherey, 1979, pp.135-36, 179), ou se ele, primeiro, teria compreendido a especificidade da posição de Spinoza sobre a negação (a negação como privação de ser pertencente exclusivamente às coisas finitas enquanto finitas), enunciada na famosa carta a Jarig Jelles de 1674 (Carta 50), e, então, teria tomado conscientemente distância de Spinoza, elaborando uma compreensão inovadora da negatividade como processo de autodiferenciação da substância. No meu ver, o debate recente sobre a compreensão da proposição omnis determinatio est negatio mostra que é oportuno ler a posição hegeliana como oposta àquela espinosana, sem disso tirar a conclusão de que Hegel estava cego diante dessa diferença (Stern, 2016). Ao mesmo tempo, a oposição entre Spinoza e Hegel mostra, por um lado, que a pretensão de Hegel de ler na proposição espinosana um início embrionário de sua lógica da negatividade absoluta precisa ser reduzida à expressão de um mero desejo, e, por outro lado, que a necessidade de explicar as diferenças do real, a partir da diferença real entre os atributos, reintroduz o problema da negatividade, que uma lógica da pura afirmação supostamente queria deixar de fora ou reduzir a um âmbito meramente proposicional (Cirulli, 2006, pp.129-130).

Em quarto lugar, a crítica da categoria de substância culmina no tratamento da categoria de interação, onde Hegel faz a transição da Lógica Objetiva para a Lógica Subjetiva. Nesse contexto, a Lógica parece restabelecer a "substância absoluta" (Hegel 2017, p.240) do espinosismo após ter criticado a aparência de uma pressuposição recíproca entre substância ativa e substância passiva na relação de 
causalidade. Porém o ciclo da categoria de causalidade mostrou que a relacionalidade absoluta não pode continuar a ser pensada como substância, pois o preço para isso seria o retrocesso lógico para a relação da substancialidade. Mas se a substância absoluta não pode recair ao nível da relação de substancialidade, então ela precisa se elevar a uma nova configuração do elemento lógico, configuração que, a partir da Lógica Subjetiva, denomina-se "conceito" ou “subjetividade”. A substância absoluta, tal qual está presente na categoria de interação, tem um caráter paradoxal, pois ela faz ressurgir a substância única de Spinoza, porém, somente para fazê-la novamente desaparecer por meio de sua Aufhebung no conceito. Esse caráter paradoxal tem a ver com a função da substância como categoria limite da Lógica Objetiva. Essa função é precisamente o que diferencia a "substância absoluta" da "relação da substancialidade", a qual ainda abstrai de todo o ciclo categorial da causalidade. Em outras palavras, a "relação da substancialidade" prescinde do necessário atravessamento crítico da relação de causalidade, enquanto a "substância absoluta" inclui esse atravessamento e constitui o limiar de uma forma nova e mais complexa de totalização. Por um lado, a substância absoluta é a categoria mais compreensiva de toda a Lógica Objetiva, a consumação de todas as estruturas categoriais do ser e da essência. Por outro lado, a substância absoluta não apenas fecha um ciclo, mas se conecta necessariamente à abertura de um novo ciclo, na medida em que a substância já esgotou todas suas potencialidades lógicas de exposição da forma absoluta. Para entender o limite da relação da substancialidade, é preciso agora adentrar na análise dessa forma de relação.

\subsection{A substância enquanto forma de relação absoluta}

A substância é a primeira de três categorias de relação absoluta, que são apresentadas como explicitações progressivas do conceito da necessidade (Notwendigkeit) e, então, como desdobramentos da concepção da essência enquanto efetividade (Wirklichkeit). Substância, causa e interação são reconstruções críticas da tábua kantiana das categorias de relação e aprofundamentos progressivos da categoria modal de necessidade. Enquanto verdade da necessidade, a liberdade terá de emergir no fim dessa série como sua plenificação e como manifestação adequada da estrutura da autorrelação negativa da essência.

A teoria hegeliana da modalidade, que ocupa o segundo capítulo (A efetividade) da terceira seção (A efetividade), constitui o requisito lógico da teoria da relação absoluta. Não podendo adentrar na análise da teoria modal, ilustrarei o caráter da relação absoluta a partir do recorte da introdução ao terceiro capítulo (A relação absoluta) da efetividade. Com a concepção da necessidade absoluta como "aquela que expõe o absoluto” (Auslegerin des Absoluten) (Hegel, 2017, p.221), a Doutrina 
da Essência entende a "exposição" (Auslegung) como um processo de "manifestação" (Manifestation). 0 absoluto que se expõe ou se manifesta é a essência progredida até a exterioridade e a inessencialidade mais extremas. Através da sua exteriorização, a essência pôs sua aparência enquanto aparência. Do ponto de vista de sua colocação sistemática, a substância não é qualquer relação, mas "relação absoluta" (absolutes Verhältnis). A relação em questão é aquela própria à Lógica da Essência, a saber, a relação que é constitutiva dos termos relacionados. Enquanto na Doutrina do Ser as relações não coincidem com a autossubsistência dos termos relacionados, na Doutrina da Essência a autossubsistência dos relacionados somente é possível na relação e como relação. É significativo que o termo "absoluto" não é mais um substantivo, mas sim um adjetivo: "absoluto" não indica aquilo que fica solto da relação, mas qualifica o modo de ser da relação. Absoluta é a relação que não tem nada fora de si que possa explicá-la; especificamente, absoluta é a relação em que a essência se medeia consigo através de seu outro (a esfera do ser). A relação absoluta significa automediação incondicionada da efetividade, porque a efetividade corresponde à unidade do ser e da essência, unidade que não se apoia em nenhuma pressuposição externa. Para Hegel, a dinâmica da efetividade é a automanifestação.

Para tornar intuitivo o movimento da necessidade absoluta que expõe a si mesma, Hegel emprega a metáfora da luz: "Como a luz da natureza não é algo, nem coisa, mas seu ser é somente seu aparecer, assim a manifestação é a efetividade absoluta igual a si mesma” (Hegel, 2017, p.221). Como na luz não há diferença entre ser e aparecer, assim, na necessidade absoluta, a unidade do ser e da essência adquiriu a forma de uma identificação total da essência com seu processo de aparecer. O “aparecer que está posto como aparência" (idem, p.221) exprime os dois aspectos da unidade do ser e da essência: por um lado, o ser é reduzido a aparência, por outro lado, a aparência não é um outro da essência, porque a essência nada mais é do que seu aparecer, isto é, o processo de gerar a aparência como manifestação determinada de si mesma.

A manifestação da essência em seu aparecer não deve sugerir que a essência se encontra sob o domínio exclusivo da identidade, pois aparecer significa produzir diferenças a partir da essência: "este diferenciar ou aparecer do absoluto é somente o pôr idêntico de si mesmo" (Hegel 2017, p.221). Isso significa que a identidade da efetividade não é algo pressuposto ao processo, porque a identidade somente pode existir como processo de autodiferenciação. Uma vez que identidade e diferença são inseparáveis, a efetividade se determina como relação absoluta, porque ela se diferencia de si de tal modo que os "momentos" diferentes constituem a "totalidade inteira" (idem, p.221). Com essa estrutura, Hegel remete à natureza da reflexão determinante, cujas determinações são termos de relações (relata) e, simultaneamente, relações determinadas. A diferença entre a relação absoluta 
e a reflexão determinante é o fato de que a primeira se expandiu por meio da reconstituição das categorias do ser, enquanto que a segunda ainda apenas negou ou eliminou a validade (pretensão de verdade) das categorias do ser.

\subsection{0 estado da pesquisa sobre a relação da substancialidade}

A porção de texto em questão não é certamente uma das mais investigadas na história das interpretações. Portanto, sua avaliação tende a variar de acordo com a maneira em que se interpreta a Lógica como um todo e, de modo mais preciso, a passagem da Lógica Objetiva para a Lógica Subjetiva. Antes de entrarmos no comentário, cabe ainda mencionar que as posições mais significativas da pesquisa sobre a relação da substancialidade se dividem grosso modo em três grupos, que giram em torno do tema geral da conexão entre Lógica e ontologia: (i) os que defendem a visão de que a Lógica de Hegel constitui uma crítica da ontologia e, simultaneamente, uma ontologia sui generis que "prossegue" a lógica transcendental de Kant (Hösle, 1988, p.55; Schick, 1994, pp.154-182; Longuenesse, 2007, p.8; Cirulli, 2006); (ii) os que leem a Lógica como uma nova ontologia especulativa não transcendental, isto é, como uma teoria das categorias fundamentais do pensar que vale, ao mesmo tempo, como teoria das categorias fundamentais do ser (Houlgate 2000); (iii) os que utilizam uma noção corrente de ontologia como teoria daquilo que há e defendem uma interpretação pragmático-transcendental da Lógica como uma análise conceitual que aborda o problema de explicitar como os conceitos fundamentais se relacionam a outros conceitos e quais representações da relação entre conceitual e não-conceitual entram no significado dos conceitos (Emundts, 2018, p.388). Dentre estas abordagens, aquela de Houlgate é a que mais se compromete com a análise dos detalhes do argumento hegeliano e que é mais consoante com a tese proposta no presente artigo.

Uma contribuição importante para a questão debatida vem do artigo recente de Hagen (2016), que analisa a relação de substancialidade no âmbito de uma reconstrução global da seção sobre a Wirklichkeit, investigada como categoria lógica, isto é, como forma ideal ou absolutamente universal que perpassa os relata sujeito e objeto, natureza e espírito, e, com isso, neutraliza a disputa sobre o idealismo e o realismo (Hagen, 2016, p.131). O interesse do estudo de Hagen consiste em mostrar que a análise da substancialidade é susceptível de dois níveis de leitura: no nível puramente interno à Lógica, a substancialidade é um estágio (deficitário, mas necessário) da apresentação progressiva da efetividade enquanto categoria lógica; no nível da referência crítica da Lógica à história da metafísica, a substancialidade é uma categoria da "metafísica de outrora" (vormalige Metaphysik), especificamente, da metafísica de Spinoza, a qual cometeria o erro de confundir as categorias lógicas 
com determinações reais e se preocuparia em aplicar as formas lógicas a objetos externos, aos quais elas - em razão de sua modalidade puramente lógica - são alheias (idem, p. 149). Diferentemente dos estudos de Longuenesse e Hösle, o trabalho de Hagen entra no conteúdo da "relação de substancialidade" e destaca sua contradição fundamental. Por causa disso, mencionaremos novamente a análise de Hagen na seção 2.

O estudo de Longuenesse (Longuenesse, 2007) sobre a lógica da essência, extraído de sua tese de doutorado, publicada em francês em 1981 e traduzida para o inglês em 2007, argumenta que o cerne revolucionário da assim chamada ontologia hegeliana (teoria do ser enquanto ser pensado) é a afirmação conjunta de que o mundo efetivo é o que é somente em virtude de uma atividade (Tätigkeit) da razão e que essa atividade fundamenta a necessidade absoluta da estrutura do mundo. 0 núcleo da interpretação de Longuenesse da efetividade (Wirklichkeit) é a teoria da modalidade (o nexo de efetividade, possibilidade, contingência e necessidade), enquanto que a reconstrução hegeliana das categorias kantianas de relação (substancialidade, causalidade, interação), por ser lembrada de passagem apenas como uma costura entre a necessidade absoluta e a liberdade enquanto conceito, não recebe mais de duas páginas (Longuenesse, 2007, pp.155-56), sem nenhuma análise das diferenças internas aos três tipos de relação. A relação de substancialidade é considerada apenas como a explicitação geral da necessidade absoluta, que transforma a unidade espinosana da natureza na unidade da reflexão e assim propõe a versão hegeliana da identidade entre natura naturans e natura naturata.

O estudo de Hösle localiza a questão da relação da substancialidade dentro de uma interpretação global da ideia hegeliana de sistema (Hösle, 1988, pp.12-57); essa ideia é considerada como o projeto de uma ontologia transcendental na qual a Lógica (entendida como doutrina das categorias finitas) e a Metafísica (entendida como ciência do princípio absoluto do real) coincidem. Embora Hösle, como já Longuenesse, se limite a resumir numa página (idem, pp.228-229) a relação da substancialidade na lógica da essência de 1813, vale a pena destacar dois pontos relevantes da sua análise. Em primeiro lugar, Hegel critica o conceito de substância de modo imanente, pelo fato de que nele teria de desaparecer tudo, isto é, não apenas a diferença entre substância e acidentes, mas também a identidade da substância enquanto base da mudança dos acidentes (idem, p.229). Em segundo lugar, Hösle releva que o conceito hegeliano de substância é problemático, porque Hegel quer, por um lado, levar adiante o conceito de substância única de Spinoza, mas, por outro lado, quando a relação de substancialidade passa para a relação de causalidade e para a interação, o conceito em questão mostra afinidades maiores com o conceito kantiano de substância, que, assim como aquele aristotélico, inclui uma pluralidade de substâncias (idem, p.228, nota 143). 
O modo de entender a crítica imanente da substância será aprofundado mais adiante na seção 2. Quanto à tensão entre unicidade e pluralidade das substâncias em Hegel, trata-se de um campo controverso. De acordo com Houlgate (2000, p.238), Hegel dá um passo além de Spinoza ao argumentar que, se a substância deve ser uma potência imanente efetiva, os acidentes precisam ser compreendidos como idênticos à potência; portanto, a substância única tem de dar origem dialeticamente a uma pluralidade de substâncias finitas que se encontram em relações de causa e efeito enquanto substâncias ativas e passivas. De acordo com Giuspoli (2000, p.152), o fio condutor da conclusão da lógica da essência é uma lógica da totalização que retoma o conceito de causa sui, com base no qual Spinoza fundamentou a unicidade da substância, de modo que pressuposição de substâncias plurais (diversas ou separadas) tornaria impossível qualquer relação absoluta. No meu ver, a tensão entre unidade e pluralidade pode ser solucionada se consideramos como Hegel deriva logicamente a pluralidade da unidade, e como, inversamente, a unidade, longe de ser um mero substrato ou uma pressuposição, se constitui como um processo de autodiferenciação que, numa determinada etapa, se consolida na oposição entre substância passiva e a substância ativa (relação da causalidade recíproca), e, no final, supera ou suprassume a contradição inerente a essa mesma oposição (interação).

Complementando Houlgate, é preciso observar que o verdadeiro passo de Hegel além de Spinoza não é a passagem da substancialidade para a causalidade, e sim a elevação da substância absoluta para a subjetividade. A tensão entre unidade da substância absoluta e pluralidade das substâncias finitas não pode ser solucionada se colocamos a Lógica de Hegel na situação de ter de escolher entre duas cosmovisões ou representações do mundo mutualmente excludentes: ou aquela monista ou aquela pluralista. A dissolução desse tipo de dilemas é justamente o que o estudo lógicodialético da categoria da substância se propõe a efetuar.

\subsection{Estratégia de exposição da relação da substancialidade}

O texto sobre a relação da substancialidade consta de sete parágrafos ${ }^{2}$ e apresenta uma estratégia expositiva bem estruturada. Em primeiro lugar, apresenta-se uma definição genética da substância enquanto primeira explicitação da determinação da necessidade absoluta (unidade do ser e da reflexão) (\$1). Em segundo lugar, começa uma análise dessa definição e, por meio dessa análise, as determinações opostas - acidentalidade, por um lado (\$2), e substancialidade, por outro lado (\$3), - são consideradas em sua aparente heterogeneidade, como se fossem âmbitos independentes da relação. Em terceiro lugar, torna-se claro que a heterogeneidade

2 Cabe notar que a numeração dos parágrafos não consta no texto original, mas é apenas uma ferramenta utilizada para auxiliar a prática do comentário. 
é somente uma forma da aparência da substância e se critica a "substância informe do representar" (\$4). Em quarto lugar, apresenta-se a identidade da identidade do aparecer e de sua diferença através do conceito-chave de "potência absoluta" (\$§56). Em quinto lugar, destaca-se a falha da relação da substancialidade e mostra-se a necessidade da transição para uma nova forma de relação absoluta (\$7). No que segue, analisarei essas etapas, deixando de lado a derivação genética da substância a partir da necessidade absoluta, derivação que a rigor caberia a uma exposição da teoria da modalidade de Hegel.

\subsection{Análise da estrutura dinâmica da relação de substancialidade}

Com a substância, caracterizada como "o ser em todo ser" (\$1) (ou seja, como ser que permanece em toda determinação e alteração do ser aí), a Lógica da Essência alcança a "última unidade da essência e do ser" (\$1). Se passamos em revista algumas das etapas da Lógica que conduziram até a substância, resulta que o imediato não refletido ou o ser puro do início da Lógica não possui nenhuma autossubsistência, pois sua verdade está contida em seu desaparecimento no nada. Na Lógica da Essência, existência e aparecimento mostram uma certa autossubsistência, mas essa ainda é relativa, pois existência e aparecimento subsistem somente em outro. Ao contrário, a substância constitui o "subsistir que é em si e para si" (\$1) frente aos acidentes. Mas como é que a substância manifesta sua absolutidade na relação da substancialidade?

Para responder a essa pergunta, Hegel se concentra, primeiramente, no "movimento da acidentalidade" (\$2). A acidentalidade é a forma dos acidentes, e esses são o conteúdo determinado da substância. A forma da acidentalidade é a contingência, entendida como conversão imediata da efetividade na possibilidade e vice-versa. 0 conteúdo da acidentalidade não é descrito empiricamente (isto é, com referência a coisas empíricas, colocadas fora do âmbito da Lógica), mas formalmente, a saber, como conteúdo categorial. Portanto, os "acidentes" não significam para Hegel meros acontecimentos, mas formas tais como "algo", a "coisa existente de múltiplas propriedades", bem como "todos que consistem de partes" e "forças que precisam da solicitação recíproca e se condicionam umas às outras” (\$6). À diferença de Aristóteles, Hegel não considera os acidentes como restritos apenas ao âmbito das qualidades transitórias dos seres, pois "acidente" designa para Hegel a característica formal das categorias do ser e também das determinações reflexivas da essência anteriores à "efetividade".

Para a descrição do conteúdo do "movimento da acidentalidade", são utilizados componentes categoriais da Lógica do Ser e da Lógica da Essência, unificados pela modalidade do aparecer, ou seja, pela modalidade reflexiva: "O movimento da acidentalidade apresenta...o aparecer uma dentro da outra das categorias do ser e 
das determinações de reflexão da essência” (\$2). Hegel exemplifica esse movimento por meio da categoria do algo, cuja estrutura, consistente na dualidade de ser em si e ser para outro, fica indiferente ao ser aí como o conteúdo se torna indiferente à forma. Uma vez que na categoria do algo o relatum e a relação subsistem como independentes, a relação do algo com seu negativo, com o outro, é um passar para o outro. 0 algo não consegue conservar sua "diversidade indiferente" frente ao outro, porque ele entra na relação com outro, altera-se e, nisso, observa Hegel, regressa ao seu fundamento. A menção do fundamento permite notar que a categoria de algo, tomada por si (na perspectiva simples da Lógica do Ser), é diferente da categoria mais complexa de acidente, pois ela deixa completamente de lado o fundamento ou a explicação da alteração do algo, ou seja, a questão se a alteração é apenas possível, contingente ou necessária. Em outras palavras, a categoria do ser deixa em suspenso se a alteração de algo depende ou não de um fundamento, e se esse fundamento é interno ou externo. 0 acidente é uma forma de pensamento mais rica do que o algo, porque é determinação reflexiva, e é reflexiva justamente porque torna explícito o fundamento da alteração. 0 algo enquanto reconduzido ao seu fundamento é o "efetivo necessário", o acidente que não pode deixar de agir diferentemente de como ele age.

Como será mostrado pelo §6, o movimento da acidentalidade promove sempre a dominação da substância na forma da contraposição sempre renovada entre a impotência dos acidentes e a potência da substância. Os acidentes são impotentes uns frente aos outros, porque não são eles mesmos a verdadeira fonte das mudanças que, de fato, produzem em suas relações recíprocas (\$6). Mas antes de descrever esse desequilíbrio, a análise hegeliana se detém no extremo da relação que é oposto ao passar e ao perecer das coisas, a saber, na "atuosidade da substância como surgir quieto de si mesma" (\$3). O termo "atuosidade" é um termo da filosofia escolástica, já usado por Spinoza para caracterizar a potência da substância como essentia actuosa (Ética, II, P 3, escólio). Hegel recorre aos termos "atuosidade" (Aktuosität) e "potência" (Macht) para deixar clara a conexão entre a relação de substancialidade e o sistema espinosista. Especificamente, o conceito de atuosidade ${ }^{3}$ quer tornar explícito o caráter plenamente ativo da efetividade: uma realidade é efetiva somente enquanto ela age, e tem tanta interioridade (essência) quanta ela é capaz de manifestar na exterioridade (ser). O surgir (hervorgehen) da substância é quieto (ruhig) enquanto não produz uma alteração da substância, mas é um surgir "de si mesma", a saber, a substância é automovimento. Aqui se torna saliente a diferença entre Hegel e Aristóteles, o qual não admitia o automovimento e concebia

\footnotetext{
3 Sobre isso, Ferrarin comenta o seguinte: "Enquanto o precursor literal do uso hegeliano de atuosidade é Spinoza e não diretamente Aristóteles, ao mesmo tempo, Hegel entende o conceito de atuosidade como autorrealização ativa, que ele associa à enérgeia aristotélica" (Ferrarin, 2001, p.406).
} 
o "repouso" como equivalente à ausência de movimento e à meta natural de todo movimento ou processo. Se o repouso é tomado em sentido dialético-especulativo, ele não pode significar que a substância é um substrato imóvel do movimento dos acidentes. Desde o início do texto, Hegel criticava a representação da substância como "um imediato abstrato que está atrás da existência e do aparecimento" (\$1). Portanto, o repouso não significa inércia, mas unicamente que a atividade da substância não é alteração ou passagem para outro, porque a substância é "como elemento simplesmente sem resistência" (\$3).

No entanto, a atividade da substância implica uma forma de contraposição, certamente não uma contraposição a um outro da substância, mas uma contraposição interna ou uma disjunção da substância. Trata-se da disjunção entre o processo em que a substância deixa sair de si os acidentes, os quais, em virtude de sua reflexão dentro de si, se tornam imediatos ou pressupostos, e o processo de negação do serpressuposto dos acidentes, ou seja, a necessidade de que os acidentes sejam mediados entre si e, além disso, mediados pela substância. 0 primeiro processo exprime aquilo que, no §5, Hegel denomina "potência criadora", enquanto que o segundo processo corresponde ao destruir dos acidentes, à negação de sua autossubsistência (prevalecer do ser posto sobre a reflexão dentro de si).

0 conceito de potência exprime como a substância se manifesta no ir e vir dos acidentes. Sua manifestação tem dois aspectos diferentes. 0 primeiro é a substância como "identidade simples do ser" (\$4). O segundo aspecto é a "alternância dos acidentes" (\$4). 0 primeiro aspecto, se absolutizado, conduz à "substância informe do representar" (§4), fixada no ser pré-reflexivo defendido por todas as filosofias da identidade, desde Parmênides até Schelling. Essa concepção da substância perde de vista algo essencial, a saber, o entrelaçamento reflexivo entre identidade e diferença, que Hegel destaca assim: "sua [da substância] diferença, na identidade simples do ser e na alternância dos acidentes nela mesma é uma forma de sua aparência" (§4). A explicitação da aparência, do momento da alternância dos acidentes, é o que permite sair da fixação ilusória da identidade e, nisso, abre o caminho para a compreensão adequada da substância e do limite que ela encontra na relação da substancialidade (§§5-6).

A alternância dos acidentes remete à substância "como potência absoluta" (\$5). A potência da substância se expressa, por sua vez, em duas maneiras: no criar e no destruir. Criar significa transpor o possível para a efetividade, destruir significa reconduzir o efetivo à possibilidade. Cabe destacar que não se trata de dois processos separados, mas sim idênticos: “o criar é destruidor, a destruição é criadora” (\$5). Na medida em que se efetiva um possível, se exclui ou se destrói a efetivação de outro. $\mathrm{Na}$ medida em que se anula um efetivo, se abre a possibilidade de realizar outros acidentes, de outros possíveis. Qualquer acidente é criado ou destruído por outro 
acidente, mas não em força de si mesmo, e sim por ele ser a expressão da potência da substância. Nesse aspecto, criar e destruir são aspectos simultâneos, contrapostos e inseparáveis da potência. Hegel fundamenta em termos reflexivos a inseparabilidade de criação e destruição: "pois o negativo e o positivo, a possibilidade e a efetividade, estão absolutamente unificadas dentro da necessidade substancial” (§5).

Cabe comentar sobre a especificidade do conceito hegeliano de potência. Em primeiro lugar, a potência não deve ser identificada com a categoria da força, na medida em que a força ainda está acometida pelo permanecer da diferença entre um interior e um exterior, diferença que constitui o limite da forma anterior da “relação essencial” (Hegel, 2017, pp. 171-190). A rigor, a força recai até mesmo na esfera da acidentalidade, porque ela descreve a relação entre os acidentes, não aquela entre acidentes e substância. Em segundo lugar, a potência não coincide com alguma faculdade ou capacidade de um sujeito agente, não somente porque falar de faculdade remete a uma esfera psicológica que ultrapassa o âmbito da Lógica, mas também porque toda capacidade, podendo ou não se realizar, não foge do limite da força já mencionado, ou, no máximo, coloca-se à altura da possibilidade formal ou daquela real. Em terceiro lugar, correndo o risco de anacronismo, podemos dizer que a potência em questão fica mais próxima da vontade de potência de Nietzsche do que da substância de Spinoza, porque, embora os três pensadores considerem as coisas como totalmente imanentes à potência, apenas Hegel e Nietzsche destacam o significado negativo ou destruidor da potência, enquanto que Spinoza nega que as coisas finitas sejam destinadas a perecer por meio daquilo que elas são em si mesmas (Houlgate, 1995, p.47). A potência da substância infinita apenas põe a essência das coisas, mas a essência não tem nenhuma negação. 0 passo de Hegel para além de Spinoza consiste em ter argumentado, com base na concepção da essência como negatividade absoluta, que a potência é simultaneamente negativa e positiva, destruidora e criadora.

A substância enquanto potência é pôr e suprassumir de seus acidentes, que constituem o campo do contingente, da aparência. Por ser contingente, o acidente é um efetivo que tem o valor da possibilidade, mas é a substância que confere esse valor aos acidentes. Por isso, não é correto dizer que um acidente domina o outro. Ao contrário, a substância é aquela que põe nos acidentes um “valor desigual” (§6) enquanto lhes atribui determinações diferentes de conteúdo e de forma (possibilidade e efetividade).

Através da potência, a substância se apresenta como processo eterno de "cisão" nas diferenças da forma e do conteúdo e como processo igualmente eterno da "purificação" dessa cisão. Enquanto “cisão" (Entzweiung) diz respeito ao caráter internamente opositivo da potência, o termo "purificação" (Reinigung) alude à libertação da unilateralidade ou do predomínio de um dos acidentes sobre os outros. 
A "purificação", portanto, equivale ao restabelecimento do primado da potência constituinte da substância sobre a potência indireta, constituída, dos acidentes.

\section{A contradição (não resolvida) da substância}

O último parágrafo (\$7) mostra que o conceito de substância não está plenamente desenvolvido por causa da restrição do movimento à esfera dos acidentes. A substância permanece, certamente, idêntica a si enquanto potência sobre os acidentes, mas, pelo fato de não agir como negatividade autorrelacional, ela recai atrás do critério de determinação da essência. Aqui está o caráter contraditório da relação de substancialidade. Por um lado, a substância está na "forma apenas de sua identidade, não de sua essência negativa" (\$7). Como idêntica a si, ela permanece numa forma de imediatidade que não exprime o caráter negativo da autoigualdade da essência. Hegel denomina "substancialidade" esse lado deficitário da substância. Mas, por outro lado, a substância "não é ativa frente a algo, mas apenas frente a si" (§3). A substância é autoatividade ou "atuosidade" (Aktuosität). Isso significa que a substância pressupõe a si mesma enquanto aparência ou acidentalidade, ou seja, como "totalidade que aparece" (\$1). Frente a esse pressuposto como ser-projetado para uma esfera aparentemente independente da substância, a substância é ativa: "O suprassumir de um pressuposto é a aparência que desaparece" (\$3). Porém, essa atividade não conduz à autossuprassunção da substância, contanto que a substância, por causa de sua "presença" (Gegenwart) imediata nos acidentes, ainda não está diferenciada realmente deles. A autossuprassunção da substância poderia ocorrer somente sob duas condições lógicas: (i) que exista uma diferença real entre o extremo da substancialidade e aquele da acidentalidade, no sentido de que ambos os extremos tenham um subsistir determinado, (ii) que essa diferença real seja suprassumida, ao mostrar que a acidentalidade não apenas contém em si a substância, mas é posta como substância, ou seja, interioriza a potência da substância e se torna, por isso, ela mesma substancial e produtora de diferenças substanciais.

Para esclarecer o déficit da substância, Hegel recorre à figura de um silogismo, em que a potência é o "termo médio" e os "extremos" são a substancialidade e a acidentalidade. 0 déficit da substância é um déficit de mediação: o termo médio (a potência) não consegue garantir um subsistir equivalente a ambos seus extremos, pois o extremo da identidade (a substancialidade) persiste, ou seja, não desaparece, enquanto o extremo da diferença (a acidentalidade) só consiste na insubsistência e no desaparecer. A saída dessa condição de desigualdade é a renuncia à absolutização do extremo da substancialidade.

A última parte do parágrafo $\$ 7$ (depois do travessão) é dedicada a descrever o desenvolvimento insuficiente da substância sob a perspectiva da falta de 
desenvolvimento dos acidentes. Pelo fato de que a substância nega apenas os acidentes, mas não nega também a si mesma, ela "tem apenas a acidentalidade por sua figura...não a si mesma". A substância comporta-se "apenas como interior dos acidentes, e estes são apenas na substância". Portanto, a substância não preenche completamente o critério lógico da relação absoluta em que ela deveria consistir. A introdução do terceiro capítulo mostrava que os relata da relação absoluta são diferenças que são elas mesmas (relata) e seu oposto, isto é, o todo enquanto unidade da relação consigo e da relação com outro: "os lados desta relação são totalidades, porque eles são como aparência” (Hegel, 2017, p.221). Se a relação de substancialidade é comparada de modo imanente com seu critério constitutivo, sua insuficiência emerge logo no fato de que a acidentalidade desaparece imediatamente no todo ou na substância. Em vez de uma compenetração entre suas diferenças ou seus extremos, a relação da substancialidade produz um desequilíbrio entre o lado da substancialidade e o lado da acidentalidade. A contradição da substância é a autoexclusão da autossubsistência da substância decorrente da incompatibilidade entre o critério interno que a relação de substancialidade deveria cumprir, a saber, o critério da relação absoluta, e a configuração unilateral que ela, de fato, dá a esse mesmo critério. 0 texto do $\$ 7$ aponta que a razão da inadequação da relação de substancialidade é o próprio extremo da substancialidade, a qual é "apenas a relação como imediatamente evanescente". Somente se a substância nega sua presença imediata nos acidentes e se transforma em "ser para si frente a um outro" (Hegel, 2017, p.221), ela abandona o estágio formal da potência, em que "as diferenças não são substanciais" (§7), para constituir-se como “relação real” (idem, p. 222) de diferenças substanciais exteriorizadas, dotadas de igual autossubsistência. Essa relação real, em que a acidentalidade é posta como diferente da substância, tendo, simultaneamente, o mesmo valor que a potência (a atividade ponente), é denominada "relação de causalidade".

Para Hagen (2016, p.150), a contradição da substancialidade é a seguinte: a substância subsiste somente no declínio dos acidentes, mas a própria substância não tem efetividade fora dos acidentes, então, ao negar a autossubsistência dos acidentes, a substância nega a condição lógica de seu próprio subsistir. Hagen salienta que a substância na relação de substancialidade é, simultaneamente, ativa e passiva, pois ela é simultaneamente potência sobre os acidentes e impotência diante deles, pois seu subsistir está condicionado pelo ir e vir dos acidentes. A duplicidade do lado ativo e do lado passivo da substância seria, de certa maneira, a reformulação hegeliana da distinção espinosana entre natura naturans e natura naturata. A substância dissolve sua própria contradição quando sua potência se comporta como potência positiva, ou seja, quando ela se dá uma efetividade externa na qual ela mesma permanece conservada como o incondicionado. Assim a substância precisa 
se configurar como uma diferença real provindo de si mesma, na qual a substância conserva sua originariedade, enquanto os acidentes adquirem uma autossubsistência distinta daquela originária e, ao mesmo tempo, posta por aquela. Nisso consistirá a situação lógica da relação entre a causa e o efeito.

Resumindo, a passagem da substancialidade para a causalidade surge da falha interna da relação da substancialidade. Precisamente, a passagem precisa ser compreendida como contradição e como exigência de manifestação da potência da substância (Iber, 2003, p.54). A problematização da substância é a elaboração de sua própria contradição. A substância deveria ser uma relação absoluta como princípio de autodiferenciação, mas a unidade da substância permanece um ser positivo que não pode ser afetado pela negação, de modo que a negação fica restringida ao lado da acidentalidade. A substância é unidade negativa, mas, ao mesmo tempo, não nega a si mesma, pois não desdobra seu núcleo de identidade: o movimento de sua autodeterminação não aparece e não é tematizado; apenas é pensado o movimento de retorno dos acidentes para dentro da substância. Nessa forma de relação desigual, a circularidade do movimento entre o todo e suas determinações é interrompida: isso impede que cada uma de suas determinações seja uma manifestação positiva do todo. Essa falha produz a passagem para a relação de causalidade, onde a causa preenche logicamente o déficit de autonegação da substância.

\section{Significado da refutação do ponto de vista do espinosismo}

Para Hegel, a conclusão da Lógica da Essência tem a forma de uma refutação (Widerlegung), a saber, de uma crítica imanente da ontologia da única substância necessária de Spinoza. Isso significa que, por um lado, Hegel reconhece a legitimidade e a necessidade do ponto de vista metafísico da substância absoluta, mas, por outro lado, o princípio da substância como causa sui resulta deficitário na medida em que Spinoza não o deriva a partir da dialética da modalidade e não o desdobra logicamente até o conceito enquanto estrutura da subjetividade absoluta. Neste respeito, em vez de progredir da substância absoluta para o conceito, o espinosismo regride da substância absoluta para a relação da substancialidade e fica preso à repetição do círculo de categorias que foram expostas acima. Em outras palavras, a crítica imanente do espinosismo como sistema da substância equivale a uma dupla operação: (i) mostrar a falha ou contradição interna da relação da substancialidade e (ii) transformar o conceito espinosano de causa sui na prefiguração especulativa do conceito hegeliano de conceito (Begriff) como desenvolvimento de si ou atividade de realização de sua finalidade interna. Nessa crítica imanente se realiza, simultaneamente, uma transformação lógico-dialética do conceito metafísico da liberdade. 
A elevação da necessidade para a liberdade não pode ser confundida com uma justificação do livre-arbítrio. A elevação da necessidade à liberdade dentro da Lógica se coloca num nível anterior à distinção entre sensível e inteligível ou entre espírito e natureza (Filosofia Real), porque a autodeterminação da necessidade ocorre por meio de uma concepção lógica da relação causal, que não pressupõe nem a referência cosmológica a séries espaço-temporais, nem uma concepção concreta de liberdade como caráter distintivo de agentes vivos e autoconscientes, tais como, por exemplo, os seres humanos. À altura da transição para a lógica do conceito, ainda não é dado saber o que significa ser um ser vivo, o que significa formar e realizar finalidades, ou o que significa a liberdade moral. Esses são conceitos que precisam ser derivados e apresentados para obter um conceito pleno de liberdade. Dentro da Ciência da Lógica, a conexão desses conceitos não é explorada na Doutrina da Essência, nem no início da Doutrina do Conceito, mas somente na segunda e na terceira seção da mesma Doutrina do Conceito.

A liberdade da qual Hegel fala na transição da Lógica Objetiva para a Lógica Subjetiva é uma dinâmica e, ao mesmo tempo, uma estrutura universalíssima de autodeterminação da realidade efetiva, não a prerrogativa de algum eu-penso, como quer que este seja pensado (como coisa pensante cartesiana ou como autoposição fichteana). A este respeito, a abertura do reino da liberdade estabelece, conforme foi antecipado na introdução do artigo, uma concepção não-subjetivista do sujeito. Isso quer dizer que Hegel defende uma teoria do sujeito diferente daquela de todas as filosofias modernas da reflexão, pois o verdadeiro sujeito da liberdade é o conceito, não o eu-penso. Apesar de uma certa tendência contemporânea a identificar em Hegel a unidade da forma conceitual com a unidade da forma da autoconsciência (especificamente, da apercepção transcendental de Kant), esta última é apenas um exemplo do conceito, exemplo que Hegel usa para esclarecer o conceito, mas não para fundamentá-lo. A liberdade enquanto autodesenvolvimento do conceito conserva a autossubsistência (Selbständigkeit) da substância absoluta, levando-a a um nível superior de autotransparência. Se admitimos a distinção entre a noção de agente e aquela de autor de um processo, podemos dizer que Hegel certamente admite, no interior da filosofia do espírito, agentes do processo da liberdade, mas não autores. A este respeito, parece correta a colocação de Longuenesse, segundo a qual "a liberdade do conceito não é a liberdade do agente histórico que "escolhe" interpretar o evento desta ou daquela maneira. E, todavia, ele [scil. o conceito] é a liberdade de um pensamento realizado em agentes históricos que cria seu objeto no próprio processo de pensá-lo" (Longuenesse, 2007, p.157). ${ }^{4}$ A confirmação eventual

\footnotetext{
4 Cabe observar que a colocação de Longuenesse serve de premissa para colocar a suspeita de que a Lógica Subjetiva corre o risco de representar um retorno ao "racionalismo triunfante" (Longuenesse, 2007, p.162), e, portanto, um passo para trás em relação à Lógica Objetiva, especialmente em relação à lógica da essência e à teoria das categorias modais, que para a autora representa "a
} 
dessa tese, porém, não se encontra na passagem da Lógica Objetiva para a Lógica Subjetiva, e sim na avaliação do nexo entre a Lógica como um todo e a Filosofia Real.

O conceito de libera necessitas, como explicado por Spinoza, constitui o conteúdo da definição 7 da primeira parte da Ethica, segundo a qual se diz livre aquela coisa que existe unicamente pela necessidade da sua natureza e que está determinada unicamente por si mesma a agir. Dessa definição emerge o valor ontológico do conceito espinosano de liberdade, segundo o qual a liberdade se vincula originariamente ao conceito de existência necessária. Neste respeito, a liberdade se manifesta como uma forma totalmente peculiar de causalidade, a saber, aquela da causa sui. Analisemos como esse conceito de causalidade se apresenta em Spinoza e Hegel.

Spinoza identifica causa primeira, causa livre e causa imanente, enquanto todos esses três modos de ser causa se apresentam como determinações da essência da substância absoluta. O conceito fundamental do qual dependem todas as demais determinações da causalidade é o de causa de si. Spinoza define causa de si como aquilo cuja essência implica a existência, isto é, como aquilo que existe somente pela necessidade da sua natureza (Ética I, def. I, 1); por sua vez, aquilo que existe unicamente pela necessidade da sua natureza é o que se diz livre (def. I, 7). Uma vez que a substância única é causa de todas as coisas no mesmo sentido em que é causa de si (Ética I, P 25, escólio), deve-se concluir que a causa de si exprime o significado originário do conceito de causalidade, enquanto incorpora tanto o significado de causa primeira quanto aquele de causa imanente. Ao mesmo tempo, a causa de si exprime uma causa livre, porque é uma atividade que se apresenta como existir e como atuar sem ser reconduzível àquela causalidade que estabelece uma relação entre coisas finitas. Justamente por não pressupor alguma finitude e limitação, a causa sui não estabelece relações que implicam alteridade ou diferença, nem inicia por si alguma coisa que caia dentro da duração. A este respeito, se a causalidade da liberdade deve expressar uma relação, ela é a posição e, simultaneamente, a superação da própria relação: por ser a relação de si consigo mesma enquanto gera ou produz seu efeito, a causa de si é a superação da alteridade da causa e do efeito. ${ }^{5}$

epítome da posição crítica de Hegel com respeito à metafísica" (Longuenesse, 2007, p.161). Diversa é a posição de Hanke (2016), o qual propõe uma tese interpretativa interessante: com sua concepção peculiar da relação entre conceito e efetividade, Hegel traz uma contribuição significativa para o debate pós-kantiano sobre a circularidade da autoconsciência, sem, por isso, cair na identificação entre a estrutura do conceito e a realidade do Eu: "Pois o problema é colocado de modo diferente: não se trata de uma autorrelação (Selbstbezug) supostamente privilegiada do sujeito, autorrelação que, então, é desmascarada como [sendo] posterior à pressuposição de si mesmo. A proposta de Hegel é que o sujeito enquanto unidade substancial da interação equitativa de autorrelação e relação-com-outro (Fremdbezug) nada mais é do que a efetividade em geral" (Hanke, 2016, pp. 177-178).

5 Para um exame detalhado das primeiras oito definições do primeiro livro da Ética como compondo a definição real de Deus, bem como para uma análise dos argumentos de Spinoza a defesa da causa sui, remeto a: Chauí, M. (1999), pp.748-792. 
$\mathrm{Na}$ dissolução da diferença entre causa e efeito como termos independentes, Hegel vê o emergir da causa infinita, na qual a causa e o efeito deixam de serem contrapostos segundo a disparidade entre um termo originário e um termo posto ou dependente. Segundo Hegel, o conceito de causa de si não se apresenta em Spinoza como completamente desenvolvido em suas potencialidades especulativas, porque a determinação da substância como causa sui é uma definição puramente assumida (isto é, não derivada a partir da dinâmica das categorias da essência), de modo que autorrelação da substância está desprovida do princípio da reflexão imanente ou negatividade absoluta. No entanto, o princípio da unicidade da substância constitui a superação da causalidade finita, que só pode existir como relação entre várias substâncias diversas, e pode ser considerado a prefiguração do conceito hegeliano da finalidade imanente.

Sabe-se que a crítica espinosana das causas finais se propõe a combater especialmente a ideia de uma finalidade externa, pela qual o telos tem uma existência independente e separada em relação àquela das coisas finitas. A ideia de uma finalidade externa se desenvolveu em conexão com aquela de uma inteligência ordenadora, com a visão antropomórfica de um Deus que tudo dirige para um fim determinado. Contanto que os seres humanos acreditam que Deus fez tudo em vista deles e que fez o ser humano para que o adorasse, não pode ter dúvida de que o finalismo é uma consequência de uma concepção antropomórfica e antropocêntrica da realidade, concepção baseada na pressuposição de um Deus transcendente, o qual é o oposto daquele "Deus sive Natura" que constitui a única base adequada para uma concepção racional do mundo.

Hegel concorda com Spinoza em reconhecer a superioridade do mecanicismo sobre a visão teleológica externa no que diz respeito à compreensão racional da natureza. Mas o filósofo alemão considera a categoria da interação (Wechselwirkung) como o início do conceito da finalidade interna, que permite diferenciar entre a causa final e a causa meramente eficiente, a saber, aquela causalidade finita que a filosofia moderna se acostumou a chamar de causa. ${ }^{6} \mathrm{~A}$ causalidade finita pertence à necessidade cega e representa a causa que, ao passar para o efeito, perde sua

6 Vittorio Morfino destacou oportunamente que o conceito espinosano de causa sui e o conceito hegeliano de Wechselwirkung não são o mesmo conceito. O segundo está marcado pela referência a um princípio de interioridade - muito embora essa interioridade se exteriorize no mundo para Hegel - e por uma teleologia implícita no processo de tornar-se sujeito da substância. Além disso, o conceito hegeliano de Wechselwirkung implicaria uma superioridade do atributo do pensamento sobre o atributo da extensão e uma concepção da temporalidade como fundação sincrônica do desenvolvimento diacrônico da totalidade mesma. Ao contrário, a causa sui de Spinoza não admitiria nenhuma hierarquia entre os atributos e excluiria qualquer concepção da natureza e da história como devir temporal da totalidade. (Morfino, 2008, pp.27-33). No meu ver, as colocações de Morfino sobre as diferenças entre Hegel e Spinoza estão corretas, mas elas não podem ser extraídas apenas da análise do conceito de Wechselwirkung, e sim precisariam de uma consideração da lógica do conceito e de sua função estruturante no sistema da lógica e da filosofia real. 
própria originariedade. A ação recíproca, enquanto verdade da causalidade, põese como uma unidade na qual o rebaixamento da causa a efeito constitui, antes, a originariedade efetiva da causa. A interação constitui assim a necessidade manifesta, a autossubsistência como relação consigo mesma. Se se quer explicar a noção de "fim" (Zweck) em termos de causalidade, ele seria a causa que se torna tal no efeito e a causa que, em sua eficácia, não passa para outro, mas se dobra sobre si mesma enquanto produz como efeito somente a si mesma. 0 conceito da finalidade marca a superação da causalidade eficiente como causalidade finita, a qual pode ser solicitada a agir apenas por uma solicitação externa.

Substância e causa podem expressar o conceito de fim segundo sua verdade somente quando são compreendidas como uma causa que seja causa de si mesma e cujo efeito seja, imediatamente, a causa. Sob esse ponto de vista, Hegel enaltece a visão especulativa da substância espinosana, que como causa sui constitui a superação não somente da causalidade eficiente finita, mas também daquela teleologia que se propõe como mera finalidade externa. Desde que seja assim transformada, a causa sui constitui a fundamentação necessária da liberdade, justamente porque consiste na libertação da autonomização do finito.

\section{Conclusão}

Gostaria de concluir resumindo os pontos centrais da problematização hegeliana da substância. Em primeiro lugar, Hegel está de acordo com Kant em compreender a substância como uma categoria de relação. Porém a ciência que investiga adequadamente essa relação não é a lógica transcendental, mas a lógica dialético-especulativa, que investiga a dinâmica do conteúdo da relação enquanto tal, suspendendo a pressuposição de que a substância só faria sentido como condição subjetiva a priori de uma experiência possível. Em segundo lugar, problematizar de modo dialético a substância significa, na Lógica da Essência, mostrar que seu conteúdo categorial abriga por si mesmo uma contradição necessária, quer dizer, constitutiva da estrutura relacional do próprio conteúdo. Em terceiro lugar, o sentido da apresentação crítica dessa contradição não consiste em mostrar que não existe nenhuma substância (ou que o conceito de substância é um conceito absurdo), mas que a categoria de substância somente realiza seu critério interno de verdade enquanto ela ganha maior complexidade e se transforma logicamente na relação de causalidade e, depois, na interação. Substancialidade e causalidade não são nem entidades reais nem ações irredutivelmente distintas de um sujeito pensante responsável pela ordem do mundo empírico, mas momentos sequenciais (graus) de autocompreensão da estrutura lógica da efetividade. 


\section{Referências:}

Berti, E. (1993). Introduzione alla metafisica. Torino, Itália: UTET.

Chauí, M. (1999). A nervura do real. Imanência e liberdade em Espinosa. São Paulo, SP: Companhia das Letras.

Cirulli, F. (2006). Hegel's Critique of Essence. A Reading of the Wesenslogik. New York \& London: Routledge.

Emundts, D. (2018). „Die Lehre vom Wesen. Dritter Abschnitt. Die Wirklichkeit“. In: Quante, M. \& Mooren, N. (orgs.) Kommentar zu Hegels Wissenschaft der Logik. Hegel-Studien. Beiheft 67. Hamburg: Meiner.

Ferrarin, A. (2001). Hegel and Aristotle. Cambridge, USA: Cambridge University Press.

Giuspoli, P. (2000). Verso la Scienza della logica. Le lezioni di Hegel a Norimberga. Trento (Itália): Verifiche.

Hagen, H. (2016). „Die Logik der Wirklichkeit: eine Entwicklung vom Absoluten bis zur Wechselwirkung“. In: Arndt, A. \& Kruck, G. (orgs.) Hegels Lehre vom Wesen. Berlin: De Gruyter.

Hanke, T. (2016). „Das Wesen im Begriff. Über den Zusammenhang von objektiver und subjektiver Logik in der Passage ,Vom Begriff im allgemeinen“". In: Arndt, A. \& Kruck, G. (orgs.) Hegels Lehre vom Wesen. Berlin: De Gruyter.

Hegel, G.W.F. (1969). Werke in zwanzig Bänden (abreviação = TW). Moldenhauer E., Michel, K.M. (orgs.). Phänomenologie des Geistes. Band 3. Frankfurt am Main: Suhrkamp.

- (2017). Ciência da Lógica, 2. Doutrina da Essência. Tradução de C. Iber e F. Orsini. Petrópolis, RJ: Editora Vozes.

Henrich, D. (1978). Hegels Logik der Reflexion. Neue Fassung. Hegel-Studien, Beiheft 18, pp. 203-324.

Hösle, V. (1988). Hegels System. Band I: Systementwicklung und Logik. Hamburg: Meiner Verlag.

Houlgate, S. (1995). Necessity and Contingency in Hegel's Science of Logic. The Owl of Minerva, 27(1), pp.37-49.

. (2000). "Substance, Causality, and the Question of Method in Hegel's Science of Logic". In: Sally Sedgwick (ed.). The Reception of Kant's Critical Philosophy. Cambridge (USA): Cambridge University Press.

Iber, C. (1990). Metaphysik absoluter Relationalität. Eine Studie zu den beiden ersten Kapiteln von Hegels Wesenslogik. Berlin/New York: Walter de Gruyter.

• (2003) „Übergang zum Begriff. Rekonstruktion und Überführung 
von Substantialität, Kausalität und Wechselwirkung in die Verhältnisweise des Begriffs“. In: Koch, A.F. \& Oberauer, A. \& Utz. K. (orgs.). Der Begriff als die Wahrheit. Zum Anspruch der Hegelschen ,Subjektiven Logik'. Paderborn: Schöningh.

Longuenesse, B. (2007). Hegel and the Critique of Metaphysics. Translated by Nicole J. Simek. Cambridge (USA): Cambridge University Press.

Macherey, P. (1979). Hegel ou Spinoza. Paris: Vrin.

Melamed, Y. (2012). “'Omnis determinatio est negatio’ - Determination, Negation and Self-negation in Spinoza, Kant and Hegel”. In: Förster E. \& Melamed, Y. (eds.). Spinoza and German Idealism. Cambridge (USA): Cambridge University Press.

Morfino, V. (2008). Causa sui or Wechselwirkung: Engels between Spinoza and Hegel. Historical Materialism 16, pp.9-35.

Nunziante, A. (2001). Monade e contraddizione. L'interpretazione hegeliana di Leibniz. Trento, Itália: Verifiche.

Schick, F. (1994). Hegels Wissenschaft der Logik - metaphysische Letztbegründung oder Theorie logischer Formen? Freiburg/München: Karl Alber Verlag.

Stern, R. (2016) "Determination is Negation": The Adventures of a Doctrine from Spinoza to Hegel to the British Idealists. Hegel Bulletin, 37, pp. 29-52. 